\title{
The compressive response of additively-manufactured hollow truss lattices: an experimental investigation
}

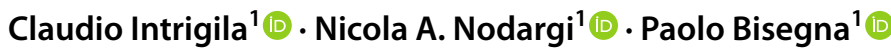

Received: 4 October 2021 / Accepted: 9 January 2022 / Published online: 6 March 2022

(c) The Author(s) 2022, corrected publication 2022

\begin{abstract}
The mechanical response of additively-manufactured hollow truss lattices is experimentally investigated under quasi-static compression testing. Exploiting the recent developments in the Fusing Deposition Modelling (FDM) technique, two families of lattices have been fabricated, obtained as tessellation in space of octet-truss and diamond unit cells. Four specimens for each family of lattices have been designed with prescribed relative density, selecting different inner-to-outer radius ratios $r / R$ of their hollow struts. Compression experiments prove that mechanical properties and failure mechanisms of hollow truss lattices are significantly dependent on the $r / R$ ratio. In particular, a shift from quasi-brittle to ductile mechanical response at increasing $r / R$ values has been revealed for the octet-truss lattice, leading to a stable collapse mechanism and increased energy absorption capacity. On the other hand, a more compliant behaviour has been observed in the diamond lattice response, with a monotonic improvement of mechanical properties as a function of the $r / R$ ratio. Such results substantiate the potentialities of additively-manufactured hollow lattice structures as an attractive solution when lightweight, resistant and efficient energy absorption materials are required.
\end{abstract}

Keywords Hollow truss lattice · Additive manufacturing · Fused Deposition Modelling (FDM) · Energy absorption efficiency $\cdot$ Compressive loading

\section{Introduction}

In the last two decades, prompted by the rapid advances in Additive Manufacturing (AM) technologies, metamaterials or Micro-Architected Materials (MAMs) have attracted enormous interest for their multi-functional purposes and engineering applications [1-6], offering a potentially effective alternative to stochastic materials like foams or honeycomb structures. Among MAMs, periodic lattices are by far the most widespread [7]. They are characterised by a unit cell at the micro-scale, which is repeated along three orthogonal axes to form a periodic structure at the

Claudio Intrigila

intrigila@ing.uniroma2.it

Nicola A. Nodargi

nodargi@ing.uniroma2.it

Paolo Bisegna

bisegna@uniroma2.it

1 Department of Civil Engineering and Computer Science, University of Rome Tor Vergata, Via del Politecnico 1, Rome 00133, Italy macro-scale. The behaviour of periodic MAMs is strictly related to the design of their unit cell. Different types of unit cells have been studied in the literature, including open reticular structures (truss-lattice, e.g. [8]), continuous shell cells [9], minimal surface sheet structures [10], just to mention a few. Focusing on open-cell lattices, particular attention has been addressed to truss-lattices for their versatile properties, depending on the different topology of the unit cell $[3,11,12]$.

The main characteristics that influence the mechanical properties of truss-lattices at the macro-scale include: (i) the unit cell topology, determined by the nodal connectivity of the struts; (ii) the unit cell morphology, characterised by shape and geometry of struts and nodes; (iii) the lattice structure morphology, defined by the spatial distribution and orientation of the unit cells; (iv) the lattice structure relative density; (v) the parent material mechanical properties.

According to the unit cell topology, and specifically to the nodal connectivity, truss-lattices are generally divided into two macro-categories [2]: stretching-dominated, whose behaviour is mainly governed by axial stresses, and bendingdominated, in which bending stresses are predominant. The 
former are characterised by a large overall structural loadbearing capacity, with high strength and stiffness-to-weight ratios. Accordingly, they find applications in the automotive, aerospace and construction industries and are employed as support structures in tissue engineering and bioprinting. Conversely, bending-dominated lattices have a more compliant behaviour, featuring a long stress plateau under compressive load and significant energy absorption capacity.

Among the different stretching-dominated truss-lattices, the octet-truss one, first proposed by Fuller [13], has been extensively studied both from a numerical and experimental point of view [12, 14-17]. Its unit cell comprises 12 nodal or vertex connections, forming a Face-Centred Cubic (FCC) configuration. Because its mechanical behaviour is governed by axial stresses [12], it offers high stiffness and strength per unit weight. Those remarkable mechanical properties have been shown for periodic octet-truss structures made by casting stainless steel and metal alloys at different scales [15, $17,18]$ or fabricated from different elastomers and polymers $[19,20]$.

Many experimental and numerical investigations have also been dedicated to evaluating and modelling the effective mechanical properties of bending-dominated lattices or to exploiting them for achieving multi-functional structures (e.g. lattices suited for seismic isolation and impact protection [21-23] or with optimised piezoelectric properties [24, 25]). In such a context, a lattice of special interest is the diamond one, which traces the crystal lattice of carbon atoms of the allotropic form. Its cell is based on an FCC configuration and comprises tetrahedral-like subunits, each consisting of four struts that meet at each node, forming an angle of $109.5^{\circ}$ [26]. Accordingly, the connectivity is equal to 4 at all nodes, i.e. it is the lowest possible for a spatial lattice structure. In recent years, diamond lattice properties have been widely investigated to design additively-manufactured implants and tissue engineering scaffolds [27-29]. By exploiting its porosity, the diamond lattice has been optimised to match the biomechanical requirements of strength, stiffness and bone ingrowth, leading to the appropriate level of tissue penetration for orthopaedic load-bearing implants [30-32].

From a morphological optimisation perspective, a very promising and challenging research field, covering both stretching- and bending-dominated response, concerns lattices with hollow struts instead of solid ones [33, 34]. Specifically, the superior performance in terms of energy absorption of metallic hollow micro-lattice with respect to honeycombs has been shown in [35] for the same relative density and parent material. Experimental investigations on ceramic-based stretching-dominated [36] and bending-dominated [37] hollow nanolattices have revealed as it is possible to simultaneously design ultrastiff, ultralight, energy-absorbing metamaterials, reversing the brittle nature of the parent material. Moreover, elastically isotropic hollow lattices have been numerically obtained in $[38,39]$, tailoring the ratio of the bendingto-axial stiffness of the constituent beams. In this context, Meza et al. [40] pointed out as the strength and stiffness parameter space of hollow lattices is highly complex and dependent upon an intricate combination of geometry and structural parameters, thus suggesting that the correlation between stretching- or bending-dominated behaviour and topology alone is insufficient. In particular, a systematic experimental investigation of the influence exerted by the inner-to-outer radius ratio of the hollow struts, which seems to be missing, might be helpful.

As a matter of fact, most of the aforementioned works are based on testing specimens manufactured, at different scales, via laser-based processes (e.g. Two-Photon Lithography (TPL), Selective Laser Melting (SLM), Stereolithography (SLA)) or via Multi Jet Fusion (MJF). Unfortunately, the precision and accuracy of those printing technologies come at the expense of their complexity and, ultimately, of their cost. Instead, very few experimental investigations have been conducted using Fused Deposition Modelling (FDM) technology, whose advantages are the simplicity of the printing process, the economical equipment and the wide availability of raw materials [41, 42]. Recent studies have highlighted the promising potential of this technology in the design and fabrication of complex geometries [43-45]. In particular, the mechanical behaviour of specific types of individual lattice structures with specific unit cell geometry for different relative density values has been investigated. However, further studies might be required to compare the mechanical response and energy absorption characteristics of 3D printed lattices of different types of unit cells made at fixed relative density [46, 47].

The present study aims to investigate the mechanical behaviour (i.e. stiffness, strength and energy absorption capacity) under a compressive load of octet-truss and diamond lattices manufactured via FDM. In particular, the lattices are designed as reticular structures composed of hollow cylindrical struts and nodes. Four different inner-to-outer radius ratios $(r / R)$ of struts, ranging from 0 (solid struts) to 0.7 , are investigated at fixed relative density value $\bar{\rho}=0.25$. The objectives of the research are: (i) to compare the different responses of hollow stretching- and bending-dominated lattice structures; (ii) to evaluate the influence of the $r / R$ ratio on the main mechanical properties of those structures at a fixed relative density; (iii) to demonstrate that it is possible to obtain interesting mechanical properties using FDM-printed lattices, whereas almost all the experimental researches have been conducted on structures manufactured using TPL, SLM and SLA [17, 36-38, 40]. The workflow is summarised in Fig. 1. 
Fig. 1 Workflow illustrating the sequence of the different phases and the related tools: from the unit cells selection to the design and fabrication process, up to the experimental validation

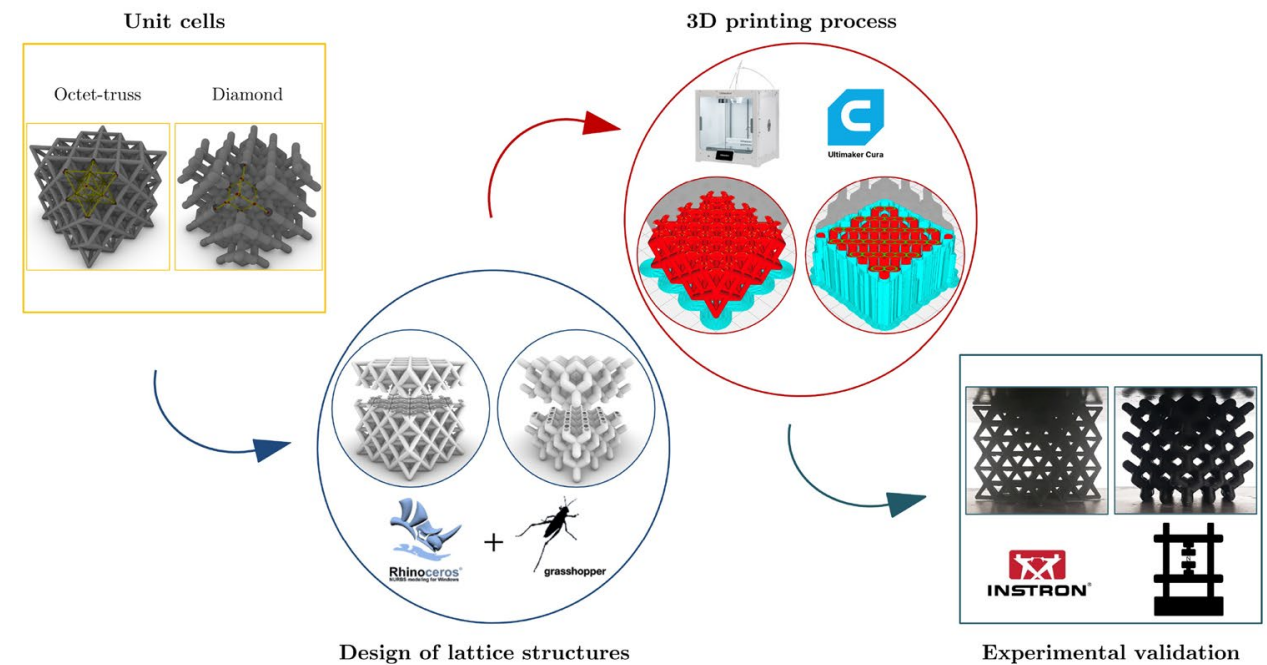

The paper is organised as follows. The design parameters of hollow lattice structures are described in Section 2. The fabrication of the specimens and the characterisation of the parent material are reported in Section 3. Experimental results of the structures tested under quasi-static compressive loading are presented in Section 4. In particular, the response of octet-truss structures is analysed in Section 4.1, whereas the results on diamond structures are reported in Section 4.2. Finally, results are discussed in Section 5, and concluding remarks are outlined in Section 6.

\section{Design of hollow lattice structures}

The present study aims to investigate the compressive response of hollow lattice structures with octet-truss or diamond unit cells. The wireframe model of the unit cells was generated within a cube of edge length $l$ equal to $16 \mathrm{~mm}$. Then, a tessellation of the unit cell along $x$-, $y$ - and $z$-axis was made to obtain a $3 \times 3 \times 3$ lattice structure. Each strut was modelled as a straight and hollow circular cylinder. The ratio between the internal radius, $r$, and the external radius, $R$, of the struts is the main geometric parameter analysed in this study. In particular, its influence on the mechanical response of the lattice structures is evaluated under uniaxial compression test.

The structures were generated by the Boolean union of hollow cylinders capped with hollow spheres. For each family (octet-truss or diamond), four different $r / R$ ratios were considered: 0 (solid struts), 0.40, 0.55 and 0.70 . For each $r / R$ ratio, internal and external radii were adjusted to ensure for each structure the same relative density, $\bar{\rho}=0.25$, evaluated as the ratio between the specimen volume and the reference wireframe volume (i.e. $48 \times 48 \times 48 \mathrm{~mm}^{3}$ ). In Fig. 2 (left), the wireframe of the unit cells and the lattice structures generated by tessellation are depicted. Furthermore, the strut cross sections and the values of the $r / R$ ratio and wall thickness, $t$, are reported in Fig. 2 (right).

By comparing the two families of lattice structures, it can be observed that the area and length of individual struts of the diamond lattice are greater than those of the octet-truss lattice. That is due to the different topology of the two elementary cells and, in particular, to the noticeable difference in the nodal connectivity (equal to 4 for diamond lattices and 12 for octet-truss lattices). The parametric geometry of the structures was implemented through the Grasshopper object programming language, available as a plug-in of the CAD Rhinoceros 3D software.

\section{Materials and fabrication}

The lattice samples were manufactured using the Ultimaker S5 desktop 3D printer (Ultimaker) through the FDM technology and the double extruder. The structural material used for printing was PLA Tough polylactic acid produced by Ultimaker. The PLA Tough filament guarantees greater workability compared to classic PLA, maintaining a strength similar to acrylonitrile-butadiene-styrene (ABS). Furthermore, PLA Tough is highly compatible with polyvinyl alcohol (PVA), a water-soluble material employed to build the supports. Starting from the STL file generated by the CAD model, the Ultimaker Cura software was used to manage and set the print configurations.

\subsection{Parent material}

With the aim to evaluate the mechanical characteristics of the parent material, five type IV tensile specimens were manufactured, as prescribed in the ASTM D638-14 [48]. Following those standards, the tensile tests were performed on the specimens using the INSTRON 4482 universal testing 
Fig. 2 Design of lattice structures: unit cells of octet-truss and diamond lattices with relative density $\bar{\rho}=0.25$. For comparison, the four $r / R$ ratios studied and the relevant thickness $t(\mathrm{~mm})$ of the hollow cylinders are reported

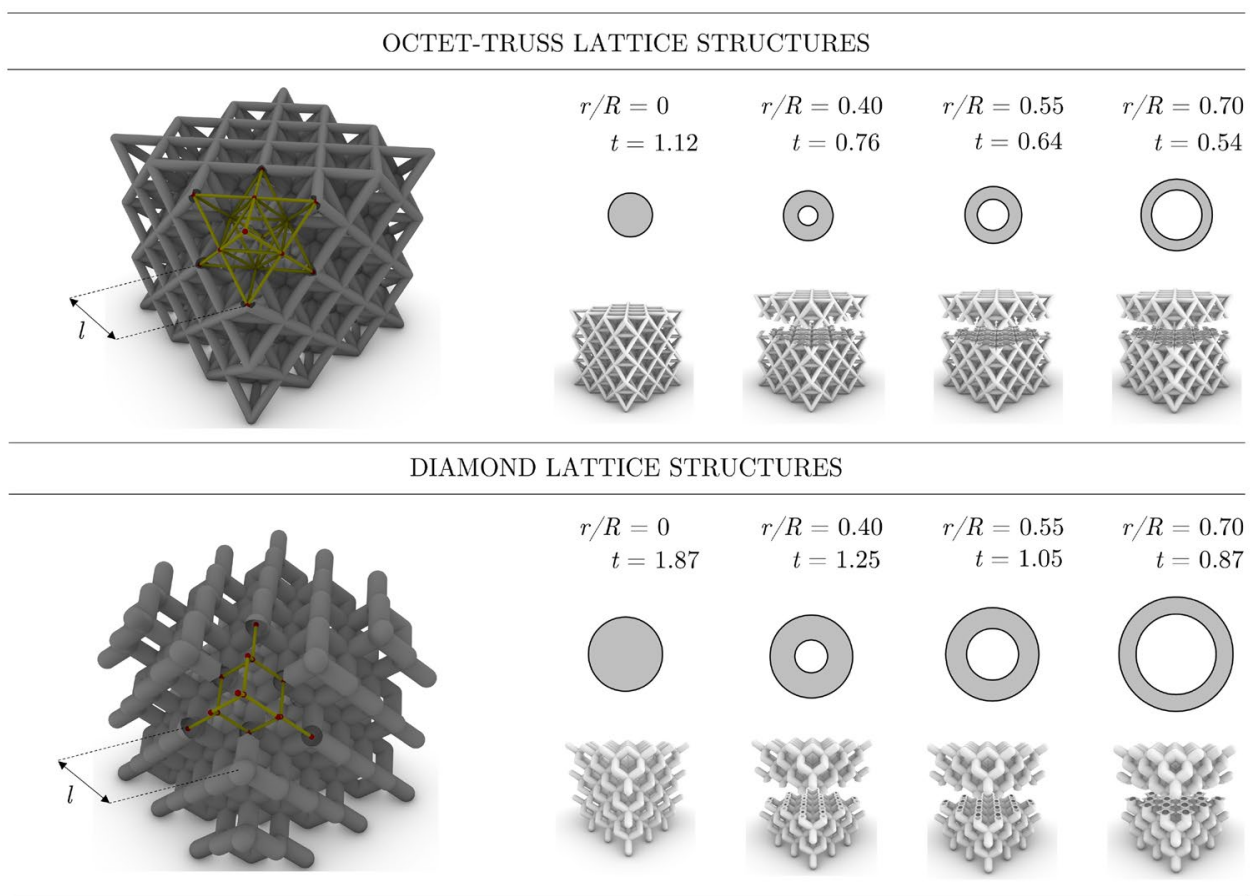

machine. A $10 \mathrm{kN}$ load cell was used to record the forces. The tests were carried out under displacement control with a constant speed of the mobile crosshead set at $50 \mathrm{~mm} / \mathrm{min}$. An extensometer was applied to the specimen, ensuring accurate measurement of the gauge length deformations. The signals of the instruments were acquired at a sampling rate of $20 \mathrm{~Hz}$, and the tests were recorded with a digital camera, with a sampling rate of $30 \mathrm{fps}$. In order to reduce the influence of the infill characteristics on the test results [49], a concentric pattern and an infill value equal to $99 \%$ were chosen. The tensile test set-up and the specimen dimensions are reported in Fig. S1 of the Supplementary Information (SI).
The resulting nominal stress-strain curves of the five specimens under uniaxial tensile loading are plotted in Fig. 3 . The trend of the curves shows an essentially brittle behaviour of the parent material, with a sharp decrease in tension after the first stress peak. The mechanical properties derived from the tensile test are summarised in Table 1, showing high repeatability of the measurements.

\subsection{Additive manufacturing}

The lattice specimens were fabricated using PLA Tough, whose characteristics have been described in the previous section. For
Fig. 3 Tensile stress-strain curves of PLA Tough material. The test speed was set at $50 \mathrm{~mm} / \mathrm{min}$, according to ASTM D638-14 [48]

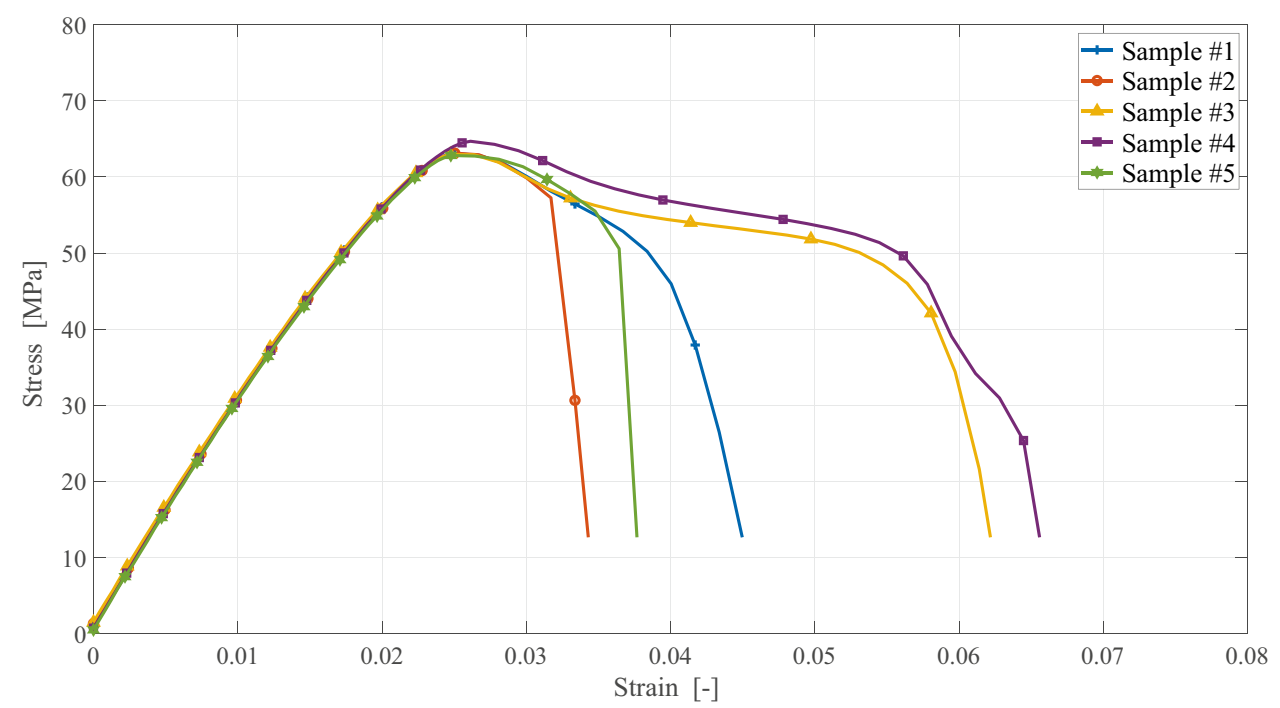


Table 1 Results of the tensile tests. The test speed was set at $50 \mathrm{~mm} / \mathrm{min}$ to evaluate the stress peaks, according to ASTM D63814 [48]. Conversely, the test speed was set at $1 \mathrm{~mm} / \mathrm{min}$ to estimate Young's modulus, using a different set of specimens (see also Table S1 and S2 in the SI)

\begin{tabular}{llll}
\hline $\begin{array}{l}\text { Specimen } \\
\#\end{array}$ & $\begin{array}{l}\text { Tensile peak } \\
{[\mathrm{MPa}]}\end{array}$ & $\begin{array}{l}\text { Strain at peak } \\
{[\%]}\end{array}$ & $\begin{array}{l}\text { Young's modulus } \\
{[\mathrm{MPa}]}\end{array}$ \\
\hline 1 & 63.1 & 2.50 & 3137 \\
2 & 63.1 & 2.50 & 3103 \\
3 & 62.9 & 2.47 & 2994 \\
4 & 64.7 & 2.61 & 3114 \\
5 & 62.8 & 2.48 & 3001 \\
Mean \pm std & $63.3 \pm 0.8$ & $2.51 \pm 0.06$ & $3068 \pm 65$ \\
\hline
\end{tabular}

the reference volume considered, a support structure in PVA was required for diamond lattices, differently from octet-truss ones, due to the longer overhangs of the individual struts in the former than in the latter [50]. Once printed, the diamond specimens were immersed in water at ambient temperature for about $12 \mathrm{~h}$ to eliminate the support structure and then dried using a compressed air machine. In order to ensure the highest possible accuracy within the limits of FDM technology and the Ultimaker S5 desktop printer, the main printing parameters of the lattice specimens were set case by case, according to the different cross sections of their members (see Table S3 of the SI for more details). The same infill settings chosen for the tensile specimens were used for the fabrication process of the lattice structures. The extrusion of the layers was set at a temperature of $210^{\circ} \mathrm{C}$, with a printing speed of $45 \mathrm{~mm} / \mathrm{s}$. All the fabricated specimens were measured and weighed, detecting an average

Fig. 4 Fabrication of designed lattice structures: (a) preview of Cura slicing software; (b) implementation phase using the Ultimaker S5 printer; (c) printed specimens before the compression test

weight of about $33.5 \mathrm{~g}$ as calculated in the design phase. The average duration for the manufacture was about $15 \mathrm{~h}$ for octettruss lattices and $20 \mathrm{~h}$ for diamond lattices due to the presence of the supports. The fabrication procedure of both octet-truss and diamond lattice structures is summarized in Fig. 4.

\section{Experimental results}

In this section, experimental results are reported, aimed at assessing the compressive response of hollow lattice structures.

The mechanical properties studied in the response of the lattice structures were strength, stiffness and absorbed energy. The strength was evaluated as the first peak stress following the elastic phase. Young's modulus was obtained as the slope of the stress-strain curve in the linear elastic region. The energy absorbed per unit volume was derived as the area subtended by the stress-strain curve from zero to the onset of the densification strain. Different methods have been proposed in the literature to identify the starting point of densification. Unfortunately, each of them presents uncertainties and is closely related to the trend of the stress-strain curve [46]. In principle, the densification strain is the strain at which the tangent modulus of the stress-strain curve of the structure approaches the elastic modulus of the parent material [51]. At densification, the relative density is almost zero, and the initial geometry of the lattice structure is no longer recognisable. In this paper, two measures of the absorbed energy were considered, using two deformation limits: (i) the Energy Absorption (EA), evaluated in the deformation range proposed in [46], which here results in 0-0.7; and (ii) the Specific

(b)
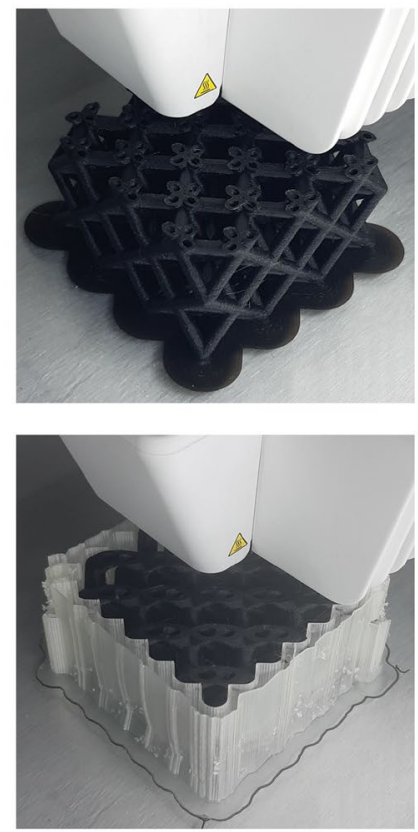

(c)
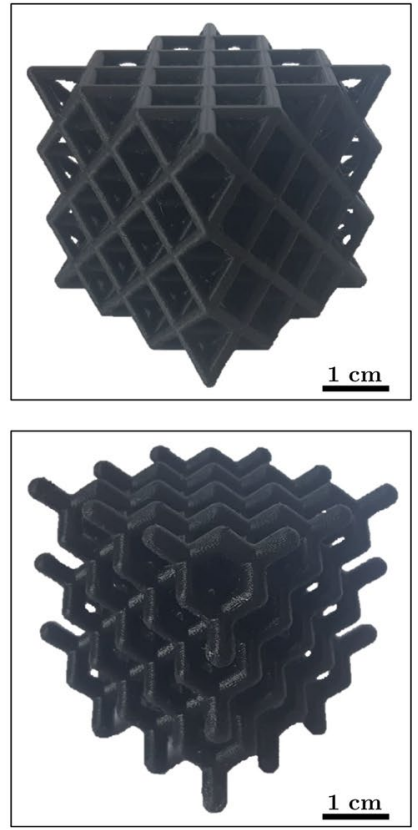
(a)

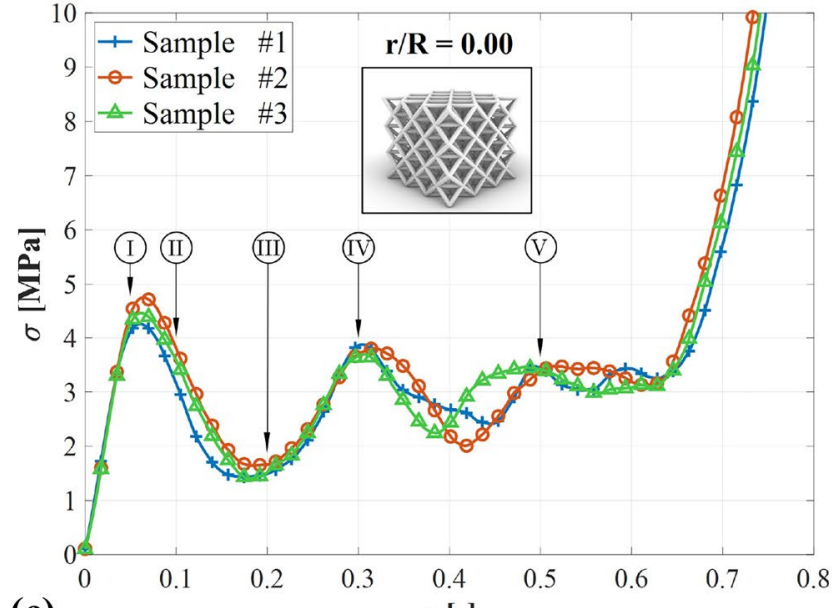

(c)

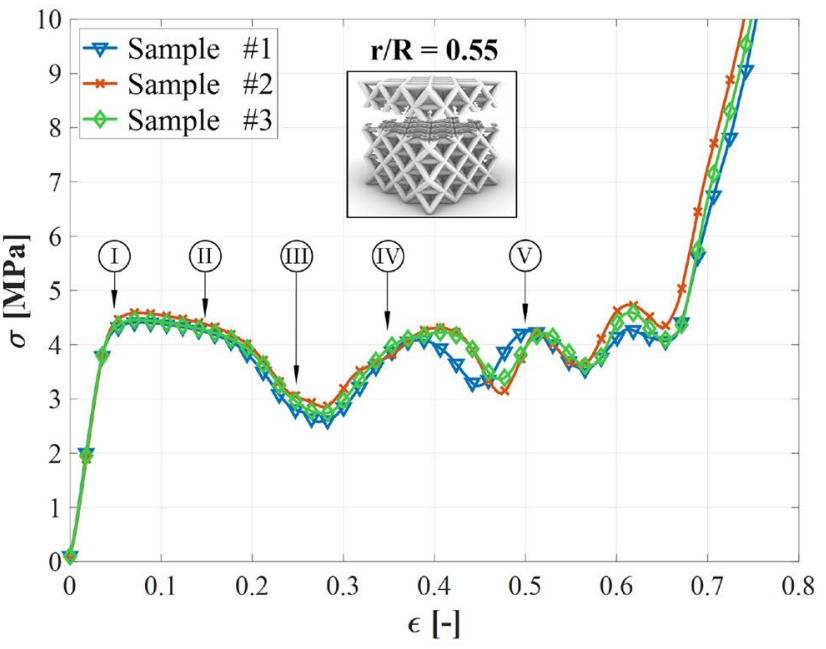

(b)

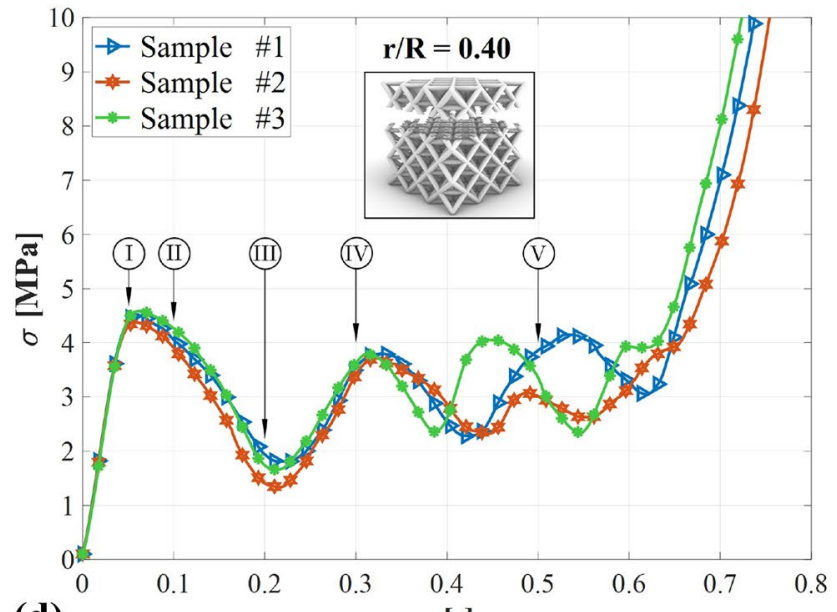

(d)

$\epsilon[-]$

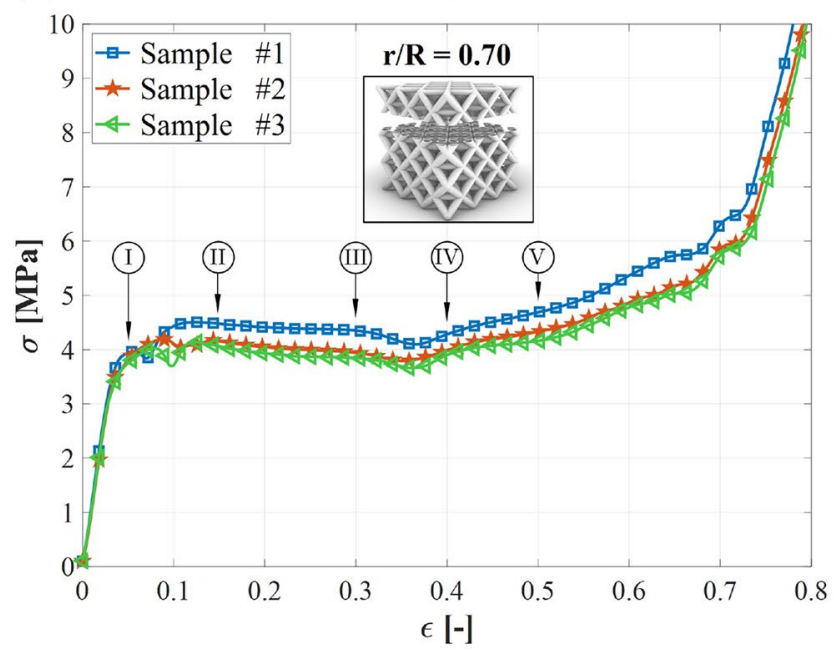

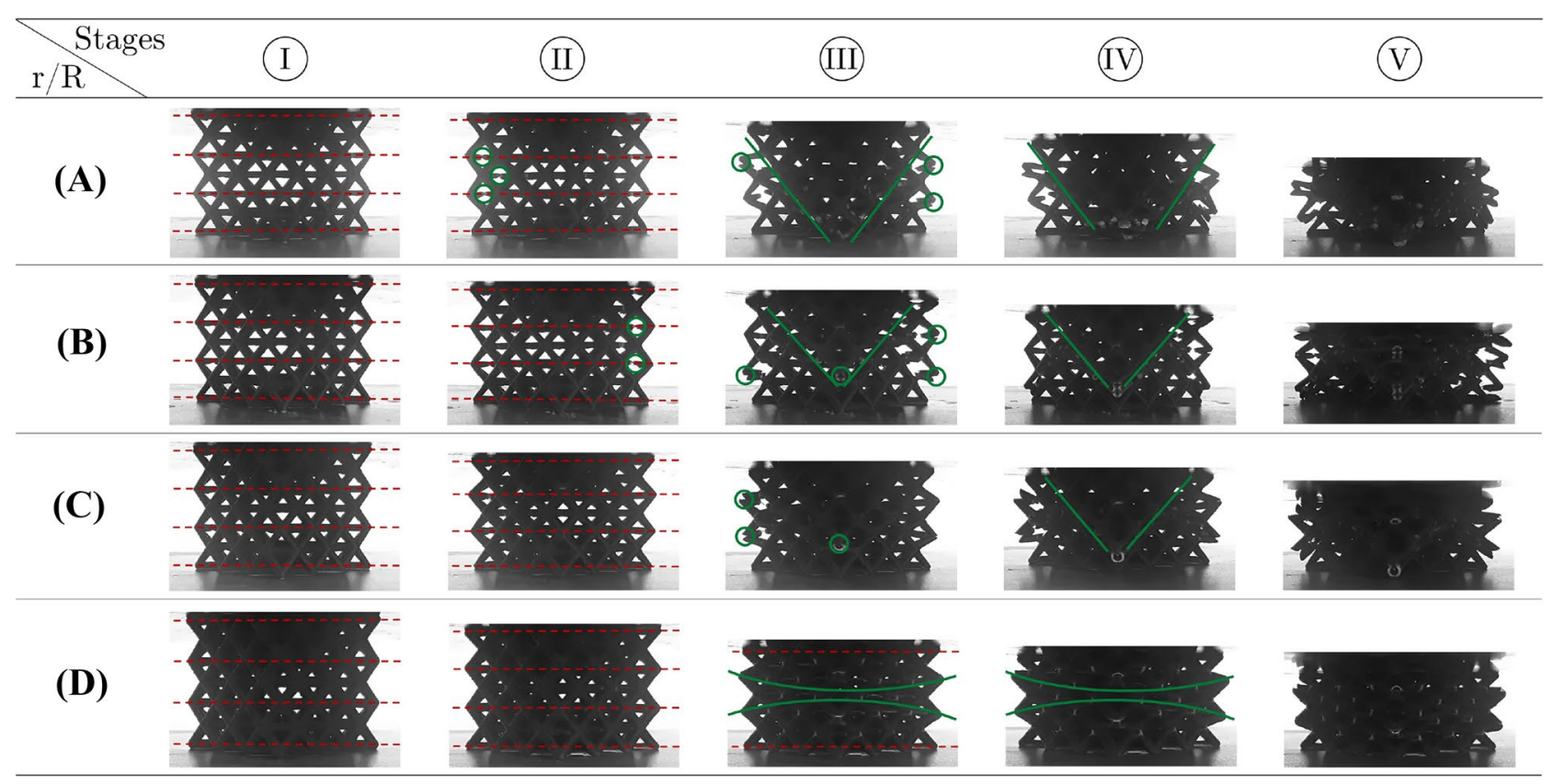


4Fig. 5 Uniaxial compressive response of octet-truss lattice specimens: in the upper part, panels (a)-(d) show stress-strain curves for $r / R$ values ranging from 0 to 0.70 . In the lower part, a table is reported showing the deformed configurations (A)-(D), respectively, relevant to the stress-strain curves (a)-(d), at deformation stages denoted by (I)-V (see also Video S1 in the SI)

Energy Absorption (SEA) defined as the ratio between the absorbed energy, calculated in the deformation range 0-0.5, and the weight of the structure, as proposed in [19].

All compression tests were performed in accordance with the standard testing method ASTM D1621-16 [52]. The tests were conducted using the INSTRON 4482 machine, equipped with a $10 \mathrm{kN}$ load cell. Experimental signals were acquired at $20 \mathrm{~Hz}$. The specimens were located between two steel plates, one fixed to the base of the machine and the other fixed to the crosshead. The loading speed rate was set as the $10 \%$ of the specimen height (in $\mathrm{mm}$ ) per minute, resulting in a nominal strain rate of $0.00167 / \mathrm{s}$. Compression tests were stopped when the deformation reached the limit of $90 \%$. This value was chosen to ensure that the densification phase was reached, remaining within the maximum capacity of the load cell. In order to eliminate the influence of the printing direction on the test results, all the specimens were positioned as fabricated and loaded along the printing direction. Three specimens were tested for each $r / R$ ratio considered in order to evaluate the repeatability of the tests and to perform a statistical analysis of the results. A total of 24 specimens were fabricated and tested.

The tests on the octet-truss lattice are reported and analysed in Section 4.1. Then, the results of diamond lattice structures are presented and discussed in Section 4.2.

\subsection{Octet-truss lattice structures}

Figure 5(a)-(d) depicts the nominal stress-strain curves of the octet-truss lattice specimens tested under quasi-static compressive loading. It is observed that all curves can be divided into three regions: (i) an elastic phase up to the first peak value, (ii) a widespread inelastic phase, and then (iii) a densification phase, accompanied by a sharp growth of the stress.

As a general remark, the stress-strain curves show a significant change in the structural behaviour of the octettruss specimens as the $r / R$ ratio increases. In fact, for low values of $r / R$, the lattice exhibits a quasi-brittle mechanical response with a significant stress drop after the elastic phase and a pronounced oscillation of the stress curve. Conversely, in the case $r / R=0.70$, the curves show a ductile behaviour with a wide stress plateau branch before the densification occurs. An intermediate behaviour is exhibited by the specimens with $r / R=0.55$. Such results allow one to drive the following considerations.
In the inelastic phase, the stress-strain curves relevant to different $r / R$ values are characterized by distinct behaviours strictly connected to the different deformation modes, as depicted in Fig. 5(A)-(D). In particular, the initial inelastic behaviour of the solid octet-truss lattice (i.e. $r / R=0$ ) is mainly stretching-dominated. First, the maximum tensile strain is reached at the middle of the external struts of the specimen central zone, as shown in the deformation stage (II) of Fig. 5(A). As the deformation increases, tensile fractures occur in those struts, thereby producing the onset of bending actions on the external nodes and leading to the opening of the same (stage (III)). These fractures cause a sharp stress reduction and strain localization in two shear bands, highlighted by solid green lines in Fig. 5(A). Then, the central zone between the two bands is progressively crushed, and the relevant struts are packed together, with a corresponding increase in stiffness and strength up to the second stress peak (stage IV). Finally, shallow oscillations in stress-strain curves due to localized settlements occur before the densification point is reached, resulting in a sudden stress rise.

In the case $r / R=0.40$, a structural behaviour very similar to that pertaining to solid struts is observed in terms of both stress-strain response and failure mode. Nevertheless, in this case, a less steep stress drop after the first peak can be observed. Consequently, a slight improvement in the energy absorption efficiency of the lattice is observed.

Conversely, for higher $r / R$ values, the inelastic structural behaviour gradually shifts towards a bending-dominated deformation, with plastic hinges at the nodes. Two main factors influence the mechanical response of these lattices: (i) hollow nodes in thin-walled beams become highly compliant in bending (as observed for hollow-beam nanolattices [40]); (ii) due to the increase in the size of the nodes, the free length of the struts is reduced. Consequently, the plastic hinges at neighbouring nodes interact with each other, leading to a diffuse zone of plastic deformation along the struts. A similar effect was found in the computational analyses of the high-relative-density octet-truss lattices with solid cylindrical struts in [17]. Regarding the deformation process of the specimens with $r / R=0.70$, no local failure can be noticed in the struts, thus preventing the formation of shear bands (see (II) of Fig. 5(D)). Accordingly, the deformation is almost uniformly distributed over the entire specimen, with a slight concentration towards the nodes in the specimen centre. Furthermore, the frictional contact at upper and lower faces of the specimens induces an arch effect, as depicted with solid green lines in the deformation stage IIII. As a result, this change in the deformation mode entails a smooth trend in the stress-strain curves, with a slight strain hardening before densification is reached at a strain value of about 0.7 . 
(a)

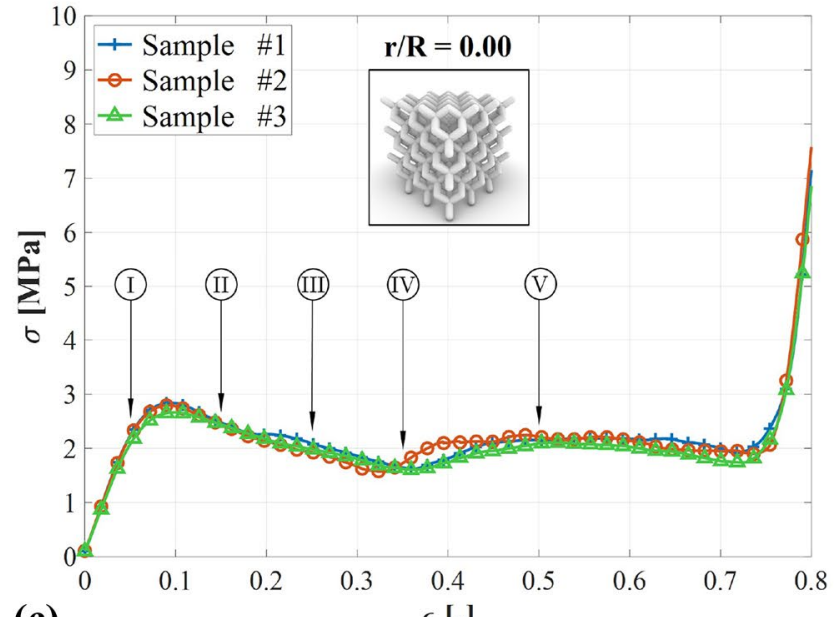

(c)

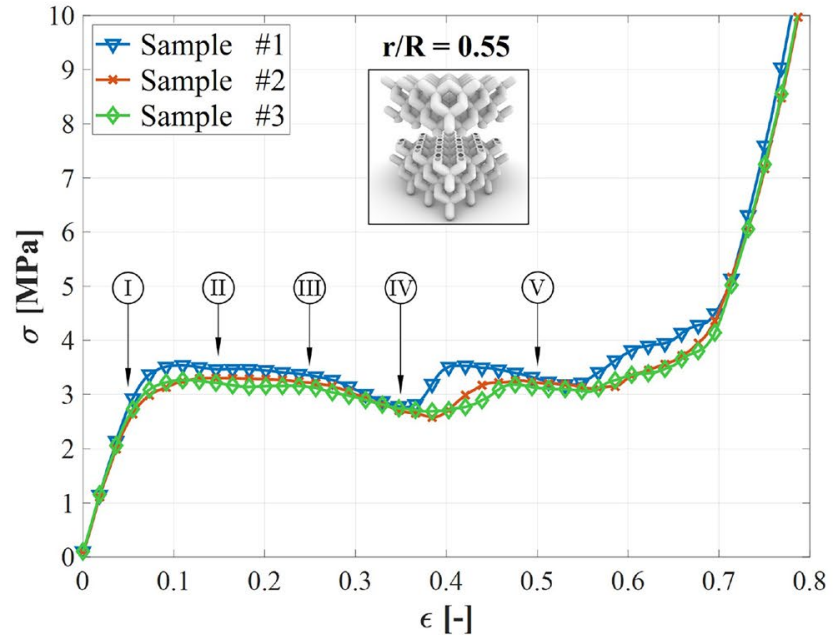

(b)

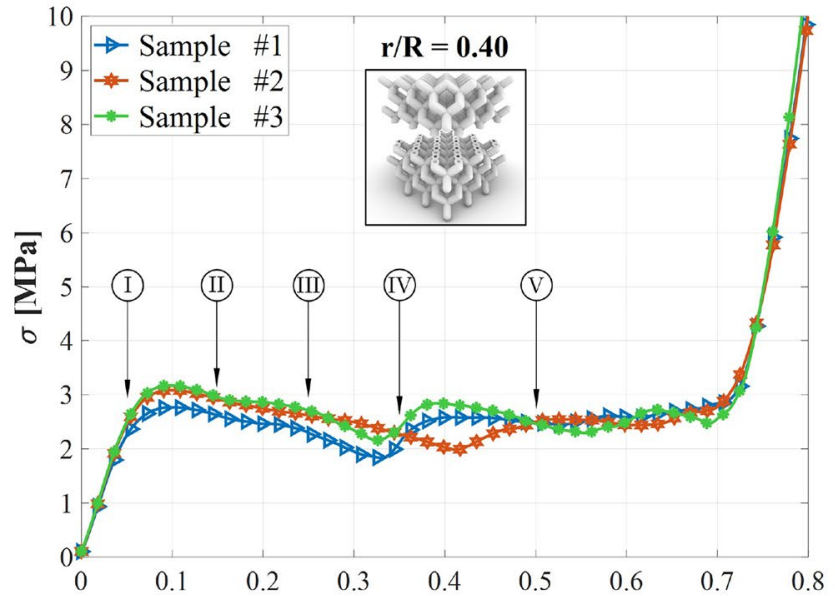

(d)

$\epsilon[-]$

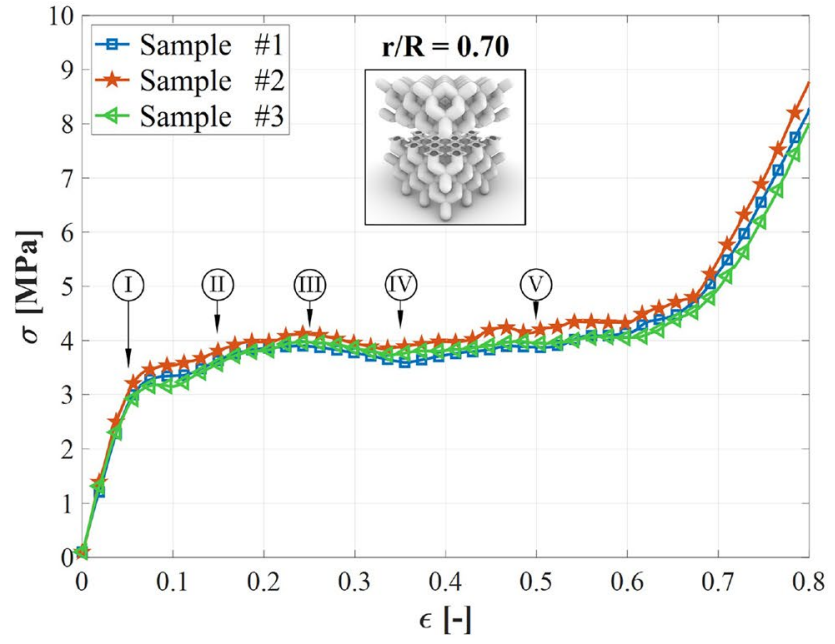

\begin{tabular}{|c|c|c|c|c|c|}
\hline $\begin{array}{l}\text { Stages } \\
\mathrm{r} / \mathrm{R}\end{array}$ & (I) & (II) & (III) & (IV) & (V) \\
\hline (A) & & & & & \\
\hline (B) & & & & & \\
\hline (C) & & & & & \\
\hline (D) & & & & & \\
\hline
\end{tabular}


4Fig. 6 Uniaxial compressive response of diamond lattice specimens: in the upper part, panels (a)-(d) show the stress-strain curves for $r / R$ values ranging from 0 to 0.70 . In the lower part, a table is reported showing the deformed configurations (A)-(D), respectively, relevant to the stress-strain curves (a)-(d), at deformation stages therein denoted by (I)- $\mathrm{V}$. The progressive deformation mode is highlighted with a transparent green hatch (see also Fig. S2 and Video S2 in the SI)

An intermediate behaviour between the previously described ones is observed in the inelastic response of the specimens with $r / R=0.55$. In particular, the trend of the stress-strain curves approaches the ductile behaviour shown in the case $r / R=0.70$ but exhibits slight oscillation due to local fractures of the external struts that characterize the response of specimens with lower values of $r / R$. A video clip of the compression test of this type of lattice structure is available in the SI, Video S1.

\subsection{Diamond lattice structures}

The nominal stress-strain curves of the diamond lattice specimens, as obtained by the static compression experiments, are illustrated in Fig. 6(a)-(d). Similarly to the curves pertaining to the octet-truss lattices, also the response of the diamond lattice specimens can be divided into three regions: (i) elastic, (ii) inelastic, and (iii) densification.

As a first remark, a similar trend of the stress-strain curves for the different $r / R$ ratios can be observed. However, differently from the octet lattice family, even in the case of solid struts, the response of the diamond lattice specimens shows an almost ductile behaviour, characterized by the lack of localized brittle phenomena as the tensile fracture of struts. In particular, increasing the imposed vertical displacement, the specimens exhibit a smooth deformation behaviour governed by internal bending actions. In Fig. 6, the main deformation stages (A)-(D) are depicted, relevant to stress-strain curves (a)-(d), respectively. The cell rows in the specimens are denoted with red dotted lines.

For all $r / R$ ratios, after the elastic limit, the onset of the inelastic phase is characterized by the bending of the unconfined external struts in contact with the upper and lower steel plates. For a better understanding of the progressive deformation mode of diamond lattices, it is noticed that the diamond unit cell presents an isometry generated by reflection in the horizontal middle plane combined with a rotation of $90^{\circ}$ about the $z$-axis. In particular, this property springs from the four tetrahedral-like subunits constituting the diamond unit cell. Therefore, the bottom face of the specimens in the views of Fig. 6(A)-(D) is indistinguishable from the top face in a view rotated by $90^{\circ}$ around $z$-axis. The increasing deformation implies a progressive crushing in the specimens, starting from the upper or lower boundaries and then spreading towards the specimen centre. The volume of lattice affected by this plastic deformation presents a rhombic pyramid shape, denoted with a transparent green hatch in Fig. 6(A)-(D) (see also Fig. S2 and Video S2 in the SI). The upward and downward orientation of this pyramid is determined by whether the deformation develops from the lower or upper face of the specimen. This is due to slight pre-existing imperfections inherent to the manufacturing process or micro-cracks generated in the first compression phase, which break the theoretical symmetry of the structure.

For low values of the $r / R$ ratio, the first branch of the inelastic response of the specimens exhibits a slight softening behaviour until a strain of about 0.35 , corresponding to the deformation stage (V) in Fig. 6(A)-(B). Subsequently, an almost perfectly plastic trend of the stress-strain curves is observed until reaching the densification phase, characterized by an abrupt stress increase. On the other hand, for the case $r / R=0.70$, the diamond lattices show a small hardening behaviour with a trend very close to that observed in the octets with the same $r / R$ ratio.

\section{Discussion}

In this section, the main mechanical properties of the tested lattice specimens are analysed and discussed in terms of strength, stiffness and energy absorption. The properties of the octet-truss lattice specimens, evaluated from stress-strain curves of Fig. 5, are reported in the bar plots of Fig. 7(a)(d). In the elastic phase, increasing the $r / R$ ratio produces an increment of Young's modulus, as found in [38], mainly due to the increasing second moment of inertia of the individual struts. The relevant values of Young's modulus are between 100 and $120 \mathrm{MPa}$. On the other hand, the stress peaks are comparable between the different octet-truss lattices with a value close to $4.5 \mathrm{MPa}$. Slightly lower values are obtained in the case $r / R=0.70$, possibly due to pronounced plastic deformations at the nodes. The observed change in the trend of the stress-strain curves, analysed in Section 4.1, is reflected in the different absorbed energy values. In fact, the energy absorption capacity rises remarkably as the $r / R$ ratio increases. In particular, from $r / R=0.40$ to 0.55 , an increase of about $20 \%$ can be noticed, both in terms of EA and SEA.

The mechanical properties of the diamond lattice structures are summarised in the bar plots of Fig. 7(e)-(h). The significant monotonic increase in all mechanical quantities at increasing the $r / R$ ratio is pointed out. As expected, the bending-dominated behaviour of diamond specimens implies lower values of strength and stiffness in comparison with octet-truss ones of equal relative density. In particular, it should be noted that these differences gradually decrease as the $r / R$ ratio increases, highlighting a more significant effect of the increase in the $r / R$ ratio in the bending-dominated structures than in the stretching-dominated ones. Concerning the energy absorption values, the diamond specimens show 
high capacity, almost comparable to that of the octet-truss lattices, especially in the case $r / R=0.70$.

As concluding remarks, the presented experimental results highlight how by tuning the ratio between the internal and external radius of the hollow struts, it is possible to obtain an overall ductile behaviour of both stretching- and bending-dominated lattice structures, even starting from an almost brittle parent material (analogous results have been derived for nanolattices in [36]). That implies a substantial improvement in the energy absorption capacity of the lattice structures, which could be exploited in designing protective devices such as explosion shielding or impact absorbers [53]. Moreover, by increasing the area moment of inertia of their struts, hollow truss lattices also increase (a)

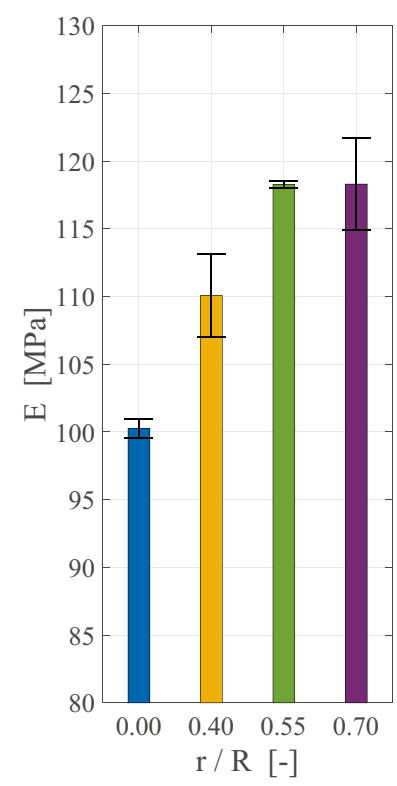

(e)

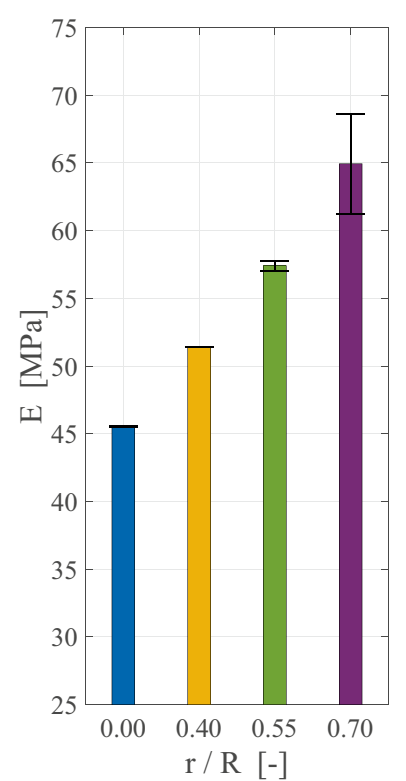

(b)

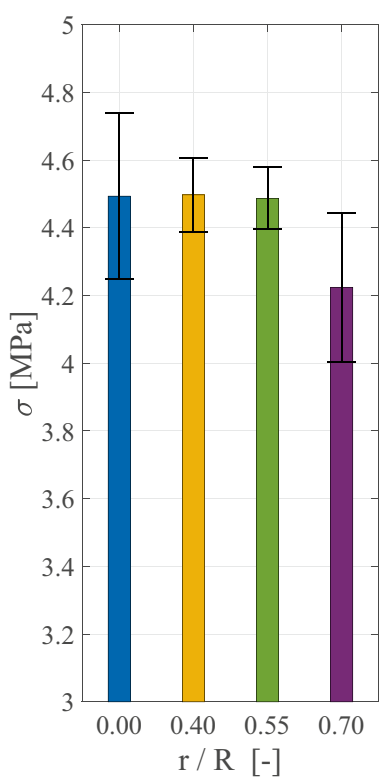

(f)

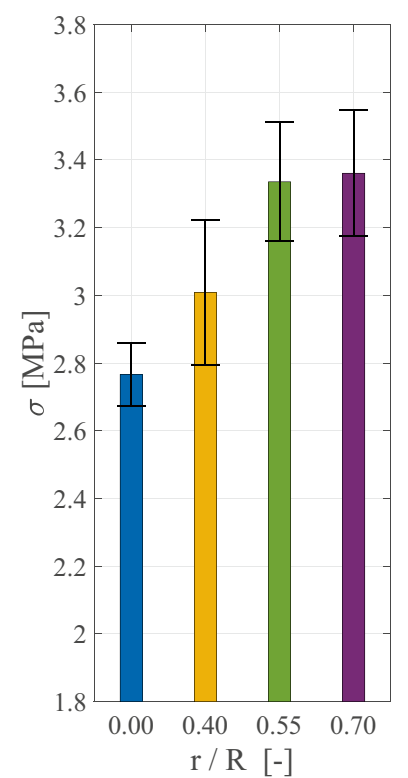

Fig. 7 Comparison of the mechanical properties obtained by compression tests in terms of Young's modulus, peak stress, energy absorption and specific energy absorption. The results pertaining to the octet-truss lattice structures, evaluated from stress-strain curves

(c)

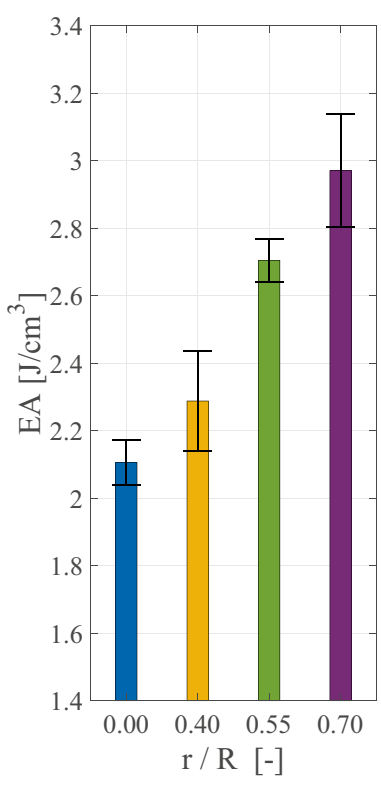

(g)

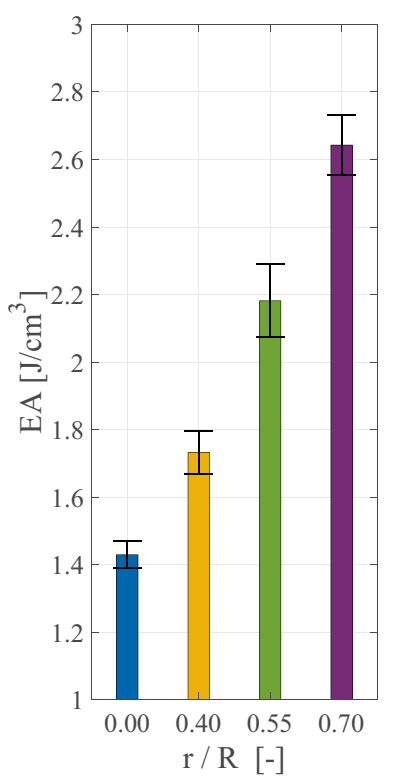

(d)

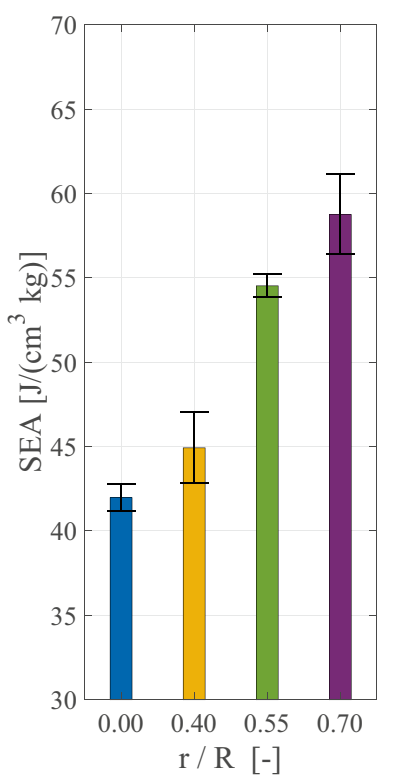

(h)

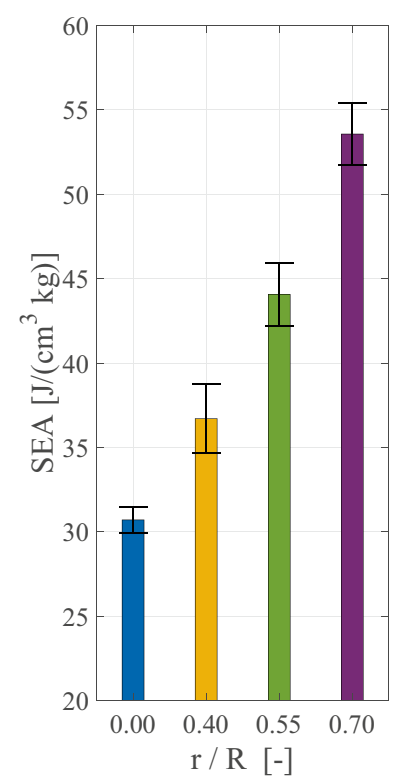

of Fig. 5, are reported in panels (a)-(d), respectively. The results relevant to diamond structures, derived by stress-strain curves of Fig. 6, are reported in panels (e)-(h) 
their resistance to Euler buckling, sometimes detected as the main failure mode in solid truss lattices [19, 20, 43]. That could be beneficial in many industrial applications where lightweight but resistant materials are required. Finally, the experimental campaign shows reasonable repeatability of the measurements in terms of both stress-strain curves and statistical results, denoting the high efficiency of the FDM printing technology in manufacturing lattice structures with complex morphology.

\section{Conclusions}

In this paper, an experimental investigation of the compressive response of hollow truss lattice structures has been presented. Two types of lattices have been fabricated, starting from the unit cell of octet-truss and diamond. Thanks to advances in FDM techniques, it has been shown how the design and manufacture of light architectures with increasingly complex morphology and high mechanical efficiency have become possible using a cheap and widely available technology. The mechanical behaviour of the 3D printed lattice structures under quasi-static compression has been investigated, focusing on the failure mechanisms and main mechanical properties such as strength, stiffness and absorbed energy. It has been experimentally observed that the increase in the ratio between the internal and external struts radius leads to a significant improvement of the mechanical properties of both stretching- and bending-dominated lattices. On the one hand, a remarkable change in the inelastic structural behaviour has been detected in the octet-truss lattices, shifting from a quasi-brittle mechanical response (characterized by initial tensile fractures of the struts) towards a bendingdominated deformation (with plastic hinges at nodes). On the other hand, a compliant behaviour has been pointed out in the diamond lattice response, with a monotonic increase in all mechanical quantities as a function of the $r / R$ ratio, especially for stiffness values. In general, the results collected in this work highlight how hollow lattice structures could be an optimal solution where lightweight, resistant and efficient energy absorption materials are required. Future investigations will explore the influence of relative density, number of unit cells, loading velocity and direction on the mechanical response of hollow truss lattices.

Electronic supplementary material The online version of this article (https://doi.org/10.1007/s00170-022-08716-0) contains supplementary material, which is available to authorized users.

Author contributions Claudio Intrigila contributed to conceptualization, methodology, formal analysis, investigation, writing-original draft, visualization. Nicola A. Nodargi contributed to conceptualization, methodology, writing-review and editing, supervision. Paolo
Bisegna contributed to conceptualization, methodology, writingreview and editing, supervision, funding acquisition.

Funding Open access funding provided by Tor Vergata University of Rome within the CRUI-CARE Agreement. The presented work was supported by the Italian Minister of University and Research through the project, "A BRIDGE TO THE FUTURE: Computational methods, innovative applications, experimental validations of new materials and technologies" (No. 2017L7X3CS) within the PRIN 2017 program, and by the University of Rome Tor Vergata through the project "Piezoelectric microArchitectured Lattice Metamaterials" (No. E84I19002400005) within the "Beyond Borders 2019" program.

Availability of data and materials The datasets generated and/or analysed during the current study are available from the corresponding author on reasonable request.

Code availability Not applicable.

\section{Declarations}

Ethics approval Not applicable.

Consent to participate Not applicable.

Consent for publication Not applicable.

Conflict of interest The authors declare no competing interests.

Open Access This article is licensed under a Creative Commons Attribution 4.0 International License, which permits use, sharing, adaptation, distribution and reproduction in any medium or format, as long as you give appropriate credit to the original author(s) and the source, provide a link to the Creative Commons licence, and indicate if changes were made. The images or other third party material in this article are included in the article's Creative Commons licence, unless indicated otherwise in a credit line to the material. If material is not included in the article's Creative Commons licence and your intended use is not permitted by statutory regulation or exceeds the permitted use, you will need to obtain permission directly from the copyright holder. To view a copy of this licence, visit http://creativecommons.org/licenses/by/4.0/.

\section{References}

1. Askari M, Hutchins DA, Thomas PJ, Astolfi L, Watson RL, Abdi M, Ricci M, Laureti S, Nie L, Freear S, Wildman R, Tuck C, Clarke M, Woods E, Clare AT (2020) Additive manufacturing of metamaterials: A review. Addit Manuf 36:101562. https://doi.org/ 10.1016/j.addma.2020.101562

2. Deshpande VS, Ashby MF, Fleck NA (2001) Foam topology: bending versus stretching dominated architectures. Acta Mater 49(6):1035-1040. https://doi.org/10.1016/S1359-6454(00) 00379-7

3. Evans AG, Hutchinson JW, Fleck NA, Ashby MF, Wadley HNG (2001) The topological design of multifunctional cellular metals. Prog Mater Sci 46(3-4):309-327. https://doi.org/10.1016/S00796425(00)00016-5

4. Fleck NA, Deshpande VS, Ashby MF (2010) Micro-architectured materials: past, present and future. Proc Math Phys Eng Sci 466(2121):2495-2516. https://doi.org/10.1098/rspa.2010.0215

5. Nazir A, Abate KM, Kumar A, Jeng JY (2019) A state-of-the-art review on types, design, optimization, and additive manufacturing 
of cellular structures. Int J Adv Manuf Technol 104(9):34893510. https://doi.org/10.1007/s00170-019-04085-3

6. Wadley HNG (2006) Multifunctional periodic cellular metals. Phil Trans R Soc A 364(1838):31-68. https://doi.org/10.1098/ rsta.2005.1697

7. Berger JB, Wadley HNG, McMeeking RM (2017) Mechanical metamaterials at the theoretical limit of isotropic elastic stiffness. Nature 543(7646):533-537. https://doi.org/10.1038/nature21075

8. Wallach JC, Gibson LJ (2001) Mechanical behavior of a threedimensional truss material. Int J Solids Struct 38(40-41):71817196. https://doi.org/10.1016/S0020-7683(00)00400-5

9. Bonatti C, Mohr D (2017) Large deformation response of additively-manufactured FCC metamaterials: From octet truss lattices towards continuous shell mesostructures. Int J Plast 92:122-147. https://doi.org/10.1016/j.ijplas.2017.02.003

10. Zhang L, Feih S, Daynes S, Chang S, Wang MY, Wei J, Lu WF (2018) Energy absorption characteristics of metallic triply periodic minimal surface sheet structures under compressive loading. Addit Manuf 23:505-515. https://doi.org/10.1016/j.addma.2018.08.007

11. Ashby MF, Gibson LJ (1997) Cellular Solids: Structure and Properties, 2nd edn. Cambridge Solid State Science Series, Cambridge University Press, Cambridge, https://doi.org/10. 1017/CBO9781139878326

12. Deshpande VS, Fleck NA, Ashby MF (2001) Effective properties of the octet-truss lattice material. J Mech Phys Solids 49(8):17471769. https://doi.org/10.1016/S0022-5096(01)00010-2

13. Fuller RW (1961) Octet truss, US Patent 2,986,241

14. Korshunova N, Alaimo G, Hosseini SB, Carraturo M, Reali A, Niiranen J, Auricchio F, Rank E, Kollmannsberger S (2021) Image-based numerical characterization and experimental validation of tensile behavior of octet-truss lattice structures. Addit Manuf 41. https://doi.org/10.1016/j.addma.2021.101949

15. Messner MC (2016) Optimal lattice-structured materials. J Mech Phys Solids 96:162-183. https://doi.org/10.1016/j.jmps.2016.07.010

16. O'Masta MR, Dong L, St-Pierre L, Wadley HNG, Deshpande VS (2017) The fracture toughness of octet-truss lattices. J Mech Phys Solids 98:271-289. https://doi.org/10.1016/j.jmps.2016.09.009

17. Tancogne-Dejean T, Spierings AB, Mohr D (2016) Additivelymanufactured metallic micro-lattice materials for high specific energy absorption under static and dynamic loading. Acta Mater 116:14-28. https://doi.org/10.1016/j.actamat.2016.05.054

18. Al-Saedi DSJ, Masood SH, Faizan-Ur-Rab M, Alomarah A, Ponnusamy P (2018) Mechanical properties and energy absorption capability of functionally graded F2BCC lattice fabricated by SLM. Mater Des 144:32-44. https://doi.org/10. 1016/j.matdes.2018.01.059

19. Ling C, Cernicchi A, Gilchrist MD, Cardiff P (2019) Mechanical behaviour of additively-manufactured polymeric octet-truss lattice structures under quasi-static and dynamic compressive loading. Mater Des 162:106-118. https://doi.org/10.1016/j.matdes.2018.11.035

20. Mohsenizadeh M, Gasbarri F, Munther M, Beheshti A, Davami K (2018) Additively-manufactured lightweight Metamaterials for energy absorption. Mater Des 139:521-530. https://doi.org/10. 1016/j.matdes.2017.11.037

21. Amendola A, Carpentieri G, Feo L, Fraternali F (2016) Bending dominated response of layered mechanical metamaterials alternating pentamode lattices and confinement plates. Compos Struct 157:71-77. https://doi.org/10.1016/j.compstruct.2016.07.031

22. Jiang Y, Wang Q (2016) Highly-stretchable 3d-architected mechanical metamaterials. Sci Rep 6:34147. https://doi.org/10. $1038 /$ srep34147

23. Neff C, Hopkinson N, Crane NB (2018) Experimental and analytical investigation of mechanical behavior of laser-sintered diamond-lattice structures. Addit Manuf 22:807-816. https://doi. org/10.1016/j.addma.2018.07.005
24. Cui H, Hensleigh R, Yao D, Maurya D, Kumar P, Kang MG, Priya S, Zheng XR (2019) Three-dimensional printing of piezoelectric materials with designed anisotropy and directional response. Nat Mater 18:234-241. https://doi.org/10.1038/s41563-018-0268-1

25. Nodargi NA, Bisegna $P$ (2021) The Saint-Venant problem for general anisotropic piezoelectric cylinders with applications to smart metamaterials design. App Math Model 93:831-851. https://doi. org/10.1016/j.apm.2021.01.003

26. Zok FW, Latture RM, Begley MR (2016) Periodic truss structures. J Mech Phys Solids 96:184-203. https://doi.org/10.1016/j.jmps. 2016.07.007

27. Ahmadi SM, Campoli G, Yavari SA, Sajadi B, Wauthle R, Schrooten J, Weinans H, Zadpoor AA (2014) Mechanical behavior of regular open-cell porous biomaterials made of diamond lattice unit cells. J Mech Behav Biomed Mater 34:106-115. https://doi. org/10.1016/j.jmbbm.2014.02.003

28. Cutolo A, Engelen B, Desmet W, Van Hooreweder B (2020) Mechanical properties of diamond lattice Ti-6Al-4V structures produced by laser powder bed fusion: On the effect of the load direction. J Mech Behav Biomed Mater 104. https://doi.org/10. 1016/j.jmbbm.2020.103656

29. Zadpoor AA, Hedayati R (2016) Analytical relationships for prediction of the mechanical properties of additively manufactured porous biomaterials. J Biomed Mater Res A 104(12):3164-3174. https://doi.org/10.1002/jbm.a.35855

30. Jetté B, Brailovski V, Dumas M, Simoneau C, Terriault P (2018) Femoral stem incorporating a diamond cubic lattice structure: Design, manufacture and testing. J Mech Behav Biomed Mater 77:58-72. https://doi.org/10.1016/j.jmbbm.2017.08.034

31. Liu F, Zhang DZ, Zhang P, Zhao M, Jafar S (2018) Mechanical Properties of Optimized Diamond Lattice Structure for Bone Scaffolds Fabricated via Selective Laser Melting. Materials 11(3):374. https://doi.org/10.3390/ma11030374

32. Wang C, Liu D, Xie Q, Liu J, Deng S, Gong K, Huang C, Yin L, Xie M, Guo Z, Zheng W (2019) A 3D printed porous titanium alloy rod with diamond crystal lattice for treatment of the early-stage femoral head osteonecrosis in sheep. Int J Med Sci 16(3):486-493. https://doi.org/10.7150/ijms.30832

33. Queheillalt DT, Wadley HNG (2005) Cellular metal lattices with hollow trusses. Acta Mater 53(2):303-313. https://doi.org/10. 1016/j.actamat.2004.09.024

34. Valdevit L, Godfrey SW, Schaedler TA, Jacobsen AJ, Carter WB (2013) Compressive strength of hollow microlattices: Experimental characterization, modeling, and optimal design. J Mater Res 28(17):2461-2473. https://doi.org/10.1557/jmr.2013.160

35. Evans AG, He MY, Deshpande VS, Hutchinson JW, Jacobsen AJ, Carter WB (2010) Concepts for enhanced energy absorption using hollow micro-lattices. Int J Impact Eng 37(9):947-959. https://doi. org/10.1016/j.ijimpeng.2010.03.007

36. Meza LR, Das S, Greer JR (2014) Strong, lightweight, and recoverable three-dimensional ceramic nanolattices. Science 345(6202):1322-1326. https://doi.org/10.1126/science.1255908

37. Deng B, Xu R, Zhao K, Lu Y, Ganguli S, Cheng GJ (2018) Composite bending-dominated hollow nanolattices: A stiff, cyclable mechanical metamaterial. Mater Today 21(5):467-474. https:// doi.org/10.1016/j.mattod.2018.03.027

38. Tancogne-Dejean T, Mohr D (2018) Elastically-isotropic elementary cubic lattices composed of tailored hollow beams. Extreme Mech Lett 22:13-18. https://doi.org/10.1016/j.eml.2018.04.005

39. Watts S (2020) Elastic response of hollow truss lattice microarchitectures. Int J Solids Struct 206:472-564. https://doi.org/10. 1016/j.ijsolstr.2020.08.018

40. Meza LR, Phlipot GP, Portela CM, Maggi A, Montemayor LC, Comella A, Kochmann DM, Greer JR (2017) Reexamining the mechanical 
property space of three-dimensional lattice architectures. Acta Mater 140:424-432. https://doi.org/10.1016/j.actamat.2017.08.052

41. Bikas H, Stavropoulos P, Chryssolouris G (2016) Additive manufacturing methods and modelling approaches: a critical review. Int J Adv Manuf Technol 83(1-4):389-405. https://doi.org/10.1007/ s00170-015-7576-2

42. Jiang J, Fu YF (2020) A short survey of sustainable material extrusion additive manufacturing. Aust J Mech Eng pp 1-10, https://doi.org/10.1080/14484846.2020.1825045

43. Kaur M, Yun TG, Han SM, Thomas EL, Kim WS (2017) 3d printed stretching-dominated micro-trusses. Mater Des 134:272280. https://doi.org/10.1016/j.matdes.2017.08.061

44. Micheletti A, Intrigila C, Nodargi NA, Artioli E, Fraternali F, Bisegna P (2021) Modeling and design of periodic lattices with tensegrity architecture and highly nonlinear response. In: Papadrakakis M, Fragiadakis M (eds) COMPDYN 2021: 8th ECCOMAS Thematic Conference on Computational Methods in Structural Dynamics and Earthquake Engineering, pp 1848-1855, https://doi.org/10.7712/120121.8605.19232

45. Yang H, Ma L (2020) 1d to 3d multi-stable architected materials with zero poisson's ratio and controllable thermal expansion. Mater Des 188. https://doi.org/10.1016/j.matdes.2019.108430

46. Arshad AB, Nazir A, Jeng JY (2020) The effect of fillets and crossbars on mechanical properties of lattice structures fabricated using additive manufacturing. Int J Adv Manuf Technol 111(3):931-943. https://doi.org/10.1007/s00170-020-06034-x
47. Habib FN, Iovenitti P, Masood SH, Nikzad M (2018) Fabrication of polymeric lattice structures for optimum energy absorption using multi jet fusion technology. Mater Des 155:86-98. https:// doi.org/10.1016/j.matdes.2018.05.059

48. Standard Test Method for Tensile Properties of Plastics (2014) ASTM D638-14, ASTM International. West Conshohocken, PA, https://doi.org/10.1520/D0638-14

49. Alaimo G, Marconi S, Costato L, Auricchio F (2017) Influence of meso-structure and chemical composition on fdm 3d-printed parts. Compos B Eng 113:371-380. https://doi.org/10.1016/j. compositesb.2017.01.019

50. Jiang J, Lou J, Hu G (2019) Effect of support on printed properties in fused deposition modelling processes. Virtual Phys Prototyp 14(4):308-315. https://doi.org/10.1080/17452759.2019.1568835

51. Ashby MF (2006) The properties of foams and lattices. Phil Trans R Soc A 364(1838):15-30. https://doi.org/10.1098/rsta.2005.1678

52. Standard Test Method for Compressive Properties of Rigid Cellular Plastics (2016) ASTM D1621-16, ASTM International. West Conshohocken, PA, https://doi.org/10.1520/D1621-16

53. Surjadi JU, Gao L, Du H, Li X, Xiong X, Fang NX, Lu Y (2019) Mechanical metamaterials and their engineering applications. Adv Eng Mater 21(3):1800864. https://doi.org/10.1002/adem. 201800864 